\title{
How similar is false recognition to veridical recognition objectively and subjectively?
}

\author{
JERWEN JOU, YOLANDA E. MATUS, JAMES W. ALDRIDGE, DAWN M. ROGERS, \\ and RYAN L. ZIMMERMAN \\ University of Texas-Pan American, Edinburg, Texas
}

\begin{abstract}
Three recognition memory experiments were conducted using modified Deese-RoedigerMcDermott (DRM) and DRM paradigms. In Experiment 1, the reaction time (RT) of the false alarms to critical nonpresented words ${ }^{1}$ (false memory) was compared with the RT of hits to the critical presented words and with the RT of hits to the studied list words (true memory). The RT of the false alarms to the critical nonpresented words was significantly longer than that of the hits to the critical words and than that of the studied list words. In Experiment 2, in addition to RT, participants' confidence level was measured on a 4-point scale for a yes or no response. Confidence rating was significantly higher for the hits to the critical presented words and to the list words than for the false alarms to the critical nonpresented words. Experiment 3 further showed that how similar false memory experience was to that of true memory was a function of retention size (number of lists of words retained in memory). In all three experiments, the participants' recognition RTs distinguished false memory from veridical memory, and in Experiments 2 and 3, so did their confidence ratings. Therefore, false memory and veridical memory differ at both the objective and the subjective levels. The results are consistent with a single familiarity dimension model of recognition memory.
\end{abstract}

In recent years, Roediger and McDermott (1995) have revived and extended a memory research paradigm first developed by Deese (1959), which is now known as the DRM paradigm. In this paradigm, participants are presented with a list of semantically associated words, such as bed, rest, awake, tired, dream, and so forth, but not with the thematically prototypical word sleep (the critical nonpresented word), and are later tested on their recall and/or recognition memory of both the critical nonpresented word and the list (or studied) words. A robust phenomenon found across numerous studies is that participants have a strong tendency to recall the critical nonpresented word or to make a false positive identification of (false alarm to) that word. The false recall or recognition rate is comparable to that for an average studied word

This study was supported in part by National Institutes of Health MBRS Grant 516753 to J.J. An earlier version of Experiment 1 was part of a presentation at the 2001 Annual Meeting of the Psychonomic Society, and an earlier version of Experiment 2 was part of a presentation at the 2003 Annual Meeting of the American Psychological Society. We thank Don Dulany for his valuable comments on the Psychonomic Society presentation (the earlier version of Experiment 1), John Seamon, Jeffrey Anastasi, Robert Greene, and an anonymous reviewer for constructive critiques on an earlier version of this article, and Theresa Norman and David Carter at UTPA for allowing their philosophy class students to participate in our experiments for extra course credit. Correspondence concerning this article should be addressed to J. Jou, Department of Psychology and Anthropology, University of Texas-Pan American, 1201 West University Drive, Edinburg, TX 78541-2999 (e-mail: jjou@panam.edu).
(McDermott, 1996; Roediger \& McDermott, 1995). It has also been found that participants typically report vivid or distinctive recollections of having seen or heard certain details of the critical nonpresented words (Gallo, McDermott, Percer, \& Roediger, 2001; Lampinen, Neuschatz, \& Payne, 1999; Payne, Elie, Blackwell, \& Neuschatz, 1996; Roediger \& McDermott, 1995).

Despite the reports on the vividness and seeming veridicality of the false memory experiences, it has also been indicated that when the critical word was presented, it was recalled and recognized at a higher rate (McDermott, 1997; M. B. Miller \& Wolford, 1999) than when it was not presented. When compared with the presented list words, the critical nonpresented words were sometimes given a slightly lower confidence rating (Toglia, Neuschatz, \& Goodwin, 1999), tended to be recalled at later positions (Payne et al., 1996; Roediger \& McDermott, 1995), and were attributed with fewer sensory, perceptual, and contextual details (Norman \& Schacter, 1997). In addition, A. R. Miller, Baratta, Wynveen, and Rosenfeld (2001) found that false recognition of critical nonpresented words produced substantially shorter P300 latencies than did true recognition of studied words. Similarly, Fabiani, Stadler, and Wessels (2000) found that lateralized brain potentials were different in a false positive recognition of the critical nonpresented words than in a true positive recognition of list words. Thus, the findings on the characteristics of false memory regarding its similarity to veridical memory are not consistent (Mather, Henkel, \& Johnson, 1997). 


\section{Reaction Times and Confidence Ratings as Dependent Measures}

In this study, we examined false recognition by measuring the reaction time (RT) of different types of recognition responses (i.e., hit, miss, correct rejection, and false alarm) in Experiment 1 and compared the RT with confidence ratings in Experiments 2 and 3. RT is a continuous response measure and, hence, may be more sensitive to small effects than are categorical response measures such as a two-category old/new judgment; or a four-category recognition judgment sure new, probably new, probably old, or sure old (McDermott \& Roediger, 1998; Roediger \& McDermott, 1995). There are also indications that response latency is more revealing of internal spontaneous cognitive processes than are verbal reports (Zuckerman, DePaulo, \& Rosenthal, 1981). In a literature review in the area of false memory, we found that three studies had used RT as a dependent measure. ${ }^{2}$ Brown, Buchanan, and Cabeza (2000) had participants make a frequency judgment on list words that were repeatedly presented for a variable number of times and critical nonpresented words. They found that a frequency judgment for the critical nonpresented words took longer than that for the list words. Hancock, Hicks, Marsh, and Ritschel (2003) had participants make a lexical decision on critical nonpresented words, list words, and nonpresented control words and found that the RT to the critical nonpresented words was shorter than those to the list words and nonpresented control words, leading them to conclude that the implicit associative response (IAR) accruing to the nonpresented word might be stronger than that to the list words. On the other hand, Fabiani et al. (2000) found a slower recognition response to the nonstudied words than to the studied words. Thus, two of the three studies in which RTs were used did not examine the RT of the false positive recognition itself, and the result of the third study that did was inconsistent with the finding of the second study. In the present study, we systematically compared the RTs of hits, false alarms, correct rejections, and misses.

We used confidence rating, in addition to RT, as converging evidence. Our confidence judgment task was somewhat different from the standard remember/know ${ }^{3}$ judgment task (Rajaram \& Roediger, 1997; Tulving, 1985). In most studies on false memory, the phenomenological experiences of false memory were measured by having participants make a remember/know judgment on the words that were judged as old (Neuschatz, Payne, Lampinen, \& Toglia, 2001; Payne et al., 1996; Roediger $\&$ McDermott, 1995; Tulving, 1985). It is possible that the subtle distinctions in the phenomenological experiences between accurate and false memories, even if accessible to the participants' conscious introspection, may not be accurately reflected in a two-category judgment. Although some studies used a four-category confidence judgment, as was noted above, it was actually not different from a two-category judgment (such as remember/know), since only two categories were provided for an item judged old or new. In Experiments 2 and 3 , we provided a four-category confidence rating for an old or new recognition judgment, respectively, in the hope that, with more gradations, the difference in the subjective experience might be more sensitively reflected in the rating. By comparing the confidence ratings with RTs, we can find out whether there is a dissociation between response speeds and participants' conscious verbal reports. Experiments 2 and 3 addressed this question.

\section{Variables Manipulated in the Experiments}

We asked several questions in this study. First, although accurate and false memories may both have vivid semantic qualities, it may be that only accurate memory has sensory and perceptual details (Johnson, Hashtroudi, \& Lindsay, 1993; Mather et al., 1997; Norman \& Schacter, 1997). If that is the case, how will these differences be reflected in the response speed? A comparison of RTs between false alarms to critical nonpresented words and hits to list words will answer this question. The second question is how repeated presentations of list words will affect the RT for critical nonpresented words. False memories may be distinguished from true memories in terms of their responses to repeated presentations. Although repeated presentation is consistently found to improve accurate memory, the findings on false memory have varied from one study to another as a function of variations in the procedural details of the learning and testing tasks (for a comprehensive review, see Seamon et al., 2002). Seamon et al. concluded that there is an interaction between presentation repetitions and word exposure duration. Under a short exposure condition (e.g., $20 \mathrm{msec}$ per word), increasing the presentation repetitions increases false memory monotonically, whereas under a long exposure duration condition ( $2 \mathrm{sec}$ per word), an initial increase in the number of presentations increases false memory, but further increases in repetitions reduce false memory, resulting in a nonmonotonic relationship between presentation repetition and false memory. We used an exposure duration longer than $2 \mathrm{sec}$ (i.e., $2.5 \mathrm{sec}$ ); therefore, we expected that repetition of presentation should lead to a decrease in the strength of false memory.

We measured the presentation repetition effect on false memory both by the false alarm rate and by the RT of the false alarms to the critical nonpresented words. We were interested in finding out whether the information in false memory gradually weakens before a categorical change in recognition decision occurs. Assume that the proportion of false alarms decreases with repetition of presentations. For the information that remains in false memory over the repetitions of presentation, does the memory strength of these bits of information become weaker with an increase in the number of presentations? If strength of memory is positively correlated with recall and negatively correlated with recognition RT (Hockley \& Murdock, 1987; Nobel \& Shiffrin, 
2001), and if the strength of false memory decreases over the repetition of presentations, the RT of the false memory should increase over the presentations. It may be that false memory weakens in a continuous manner before it reaches a threshold at which it is rejected as new in a recognition decision. Conversely, the strength of true memory may increase with repetition of presentations, leading to a decrease in RT. Both Experiments 1 and 2 tested this hypothesis.

In Experiments 1 and 2, we used a variation of the standard DRM paradigm for the recognition test. We used a 30 -word recognition test list by adding 14 semantic associates to the original 15-word list (plus 1 critical word) in Roediger and McDermott's (1995) study. Half of the 30 associates were presented at study, and half were used as distractor words in the recognition test. The primary purpose was to find out whether participants would use a more stringent criterion when all the distractor words were related and, hence, would lower their false alarm rate for the critical nonpresented words (i.e., false memory rate). In Experiment 3, we used a standard DRM recognition test (with unrelated words used as noncritical distractors). However, unlike in a standard DRM recognition test, in which the recognition test is not given until the participants have learned typically a dozen or more lists of words, we varied the number of lists the participants learned before they were given the recognition test. Therefore, by comparing the results of Experiments 1 and 2 with those of Experiment 3, we hoped to find out whether or how the word list composition variable would affect the rate of false alarms to the critical nonpresented words and the RT difference between the critical nonpresented words and the list words.

\section{EXPERIMENT 1}

The main purpose of Experiment 1 was to determine whether there is any difference in response speed between an accurate positive recognition of a critical presented word and a false positive recognition of a critical nonpresented word and, more important, whether there is a difference in RT between an accurate positive recognition of a list word (the veridical memory) and the false positive recognition of a critical nonpresented word (false memory). Also, we compared RT and accuracy across three presentation frequencies to determine the effect of repeated presentations on false memory and to see whether there would be any gradual change in the strength of false memory that might be reflected in the RT before the piece of information was rejected in recognition. For each question examined, we sought converging evidence in both RTs and recognition rates.

\section{Method}

Participants. One hundred thirty-four undergraduate psychology students participated in the experiment - 49 in the one-presentation, 43 in the two-presentation, and 42 in the three-presentation condi- tions - for extra course credit. All the participants had English as their native language.

Materials and Design. Twenty-four lists of 30 words each of semantically associated words were constructed. Each list was an extension of each of the 24 lists of words used in Roediger and McDermott (1995; 15 semantic associates and 1 critical nonpresented word on each list). The other 14 words were selected from Russell and Jenkins's (1954) associated word norms. ${ }^{4}$ The first 15 words were listed in the same order as that in Roediger and McDermott's study, and the additional 14 words that followed the first 15 words were listed in the same order as that in Russell and Jenkins's norms. Thus, the words were ordered in the descending association value. These words are shown in the Appendix. The 24 lists were divided into three blocks, with the first block consisting of the 1 st to 8 th, the second block the 9 th to the 16 th, and the third block the 17 th to the 24 th lists. One third of the participants studied and were tested on the first block, one third on the second block, and one third on the third block of lists. This arrangement was made to keep the experiment from running too long but, at the same time, to maximize the material sample base and, hence, its generalizability. The 8 lists of words in a block were presented in a different random order for each participant.

Depending on the assigned participant's number, the computer program selected the first, the second, or the third block of eight lists of words for study and test for that particular participant (e.g., Participants 1, 4, and 7 received Block 1, Participants 2, 5, and 8 received Block 2, and Participants 3,6, and 9 received Block 3 ). After the block to be used was determined, for the odd-numbered participants, the computer program selected the critical words of the oddnumbered lists in the block for presentation (and the critical words of the even-numbered lists were not presented). In addition, for the odd-numbered participants, the odd-numbered words from each of the eight lists were selected for presentation, and the rest of the words were used as distractors. The arrangement was reversed for the even-numbered participants. Therefore, each critical word was presented for half of the participants and not presented for the other half of the participants. The frequency of presentation (one, two, or three presentations) was manipulated between participants. Thus, a separate group of participants served in each of the three presentationfrequency conditions.

Procedure. The participants were tested individually on a computer in a small cubicle. The 15 target words were presented in a different random order for each list and for each participant at the center of a monitor for $2.5 \mathrm{sec}$ per word, with a 1 -sec blank screen between the presentations of one word and the next. The word was shown in Times New Roman font size 12 in white against a black background. At the end of the sequential presentation, the participants were asked to count backward by threes for $30 \mathrm{sec}$, starting from a three-digit random number that was displayed along with a question mark prompt. The participants responded by typing the next smaller number into the space and following it by a press of the Enter key. When the participants gave a wrong number, a warning was displayed along with a beep. In that case, the participants had to reenter the correct number to continue. When the $30 \mathrm{sec}$ of backward counting expired, the recognition test began.

In the recognition test, the probe word was displayed at the center of the monitor. The participants were instructed to press the " $\mathrm{z}$ " key if they judged that they had seen that word at study and the "/" key if they judged that they had not seen that word. The two response keys were counterbalanced across the participants. There was a 1-sec blank screen between the end of pressing the response key and the appearance of the next probe word. The participants were told not to rest while the stimulus word was being displayed, since their response time was measured by the computer. They were also told that if their responses were random, the computer would 


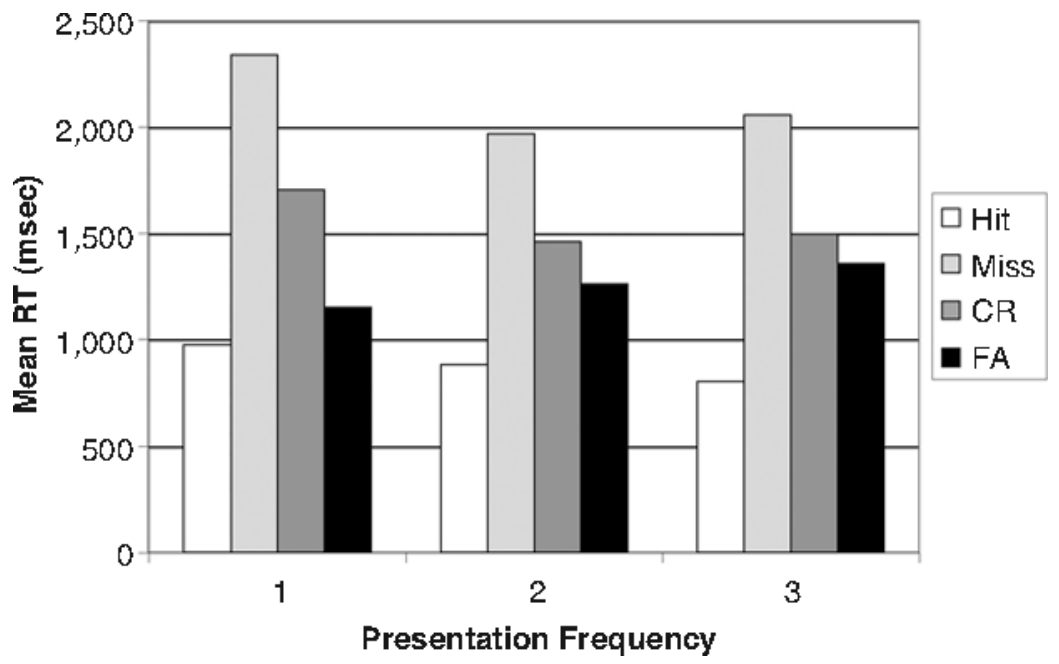

Figure 1. Mean reaction times (RTs, in milliseconds) as a function of presentation frequency and response category for the critical words in Experiment 1 (CR, correct rejection; FA, false alarm).

detect the random pattern and that they would be asked to repeat the experiment. Nobody actually repeated the experiment.

\section{Results and discussion}

Analysis of RT data. RTs that were equal to zero or were 15,000 msec or longer ${ }^{5}$ were excluded from analysis. These trials made up $0.05 \%$ of the data. All significant $p$ levels were either equal to or smaller than .05 unless otherwise noted. The mean RTs for the critical words as a function of response category (hit, miss, correct rejection, and false alarm) and of presentation frequency $(1,2$, and 3$)$ are presented in Figure 1, and those for the noncritical words are presented in Figure 2.

The first planned analysis of variance ${ }^{6}$ (ANOVA) conducted was to compare the RTs of the hits and false alarms for the critical words, with presentation frequency as a between-subjects factor and response category as a withinsubjects factor. As can be seen in Figure 1, overall, the false alarms to the critical nonpresented words (mean RT $=$ $1,325 \mathrm{msec}$ ) took significantly longer than did the hits to the critical presented words [ $893 \mathrm{msec} ; F(1,112)=51.24$, $\left.M S_{\mathrm{e}}=235,441\right]$. The longer RT for the false alarms than for the hits suggests that perhaps, at the sensory and perceptual level, the two types of positive recognition are different. If the memory trace of the critical nonpresented words are created by IAR (Underwood, 1965), the quality of the trace may be different from one created from an IAR plus a perception of the external stimulus (Johnson, Foley, Suengas, \& Raye, 1988; Mather et al., 1997). Thus, the RT result for the hit and false alarm responses to the critical words seemed to be consistent with the idea of additive activation from internal and perceptual sources.

As can be seen in Figure 1, there was a decrease in RT for hits but an increase for false alarms as the presentation frequency increased from one to three. This pattern was confirmed by a significant interaction between response category and presentation frequency $[F(2,112)=$ $\left.3.59, M S_{\mathrm{e}}=235,441\right]$. There are several implications of this result. First, the decreasing RT of the hits suggests that as learning increases, accurate memory strength increases, not only in the form of increasing proportion of correct recognition, but also in the form of decreasing RT. Second, the RT result for the false alarms is not consistent with Underwood's (1965) IAR account of false memory in the DRM paradigm. This RT result provides converging evidence for findings from studies in which the same conclusion about the IAR was reached but recall or recognition rate was used as a dependent measure (Benjamin, 2001, for young adults at a slow pace of presentation; McDermott, 1996; McDermott \& Watson, 2001; Seamon et al., 2002; Tussing \& Greene, 1999, Experiment 5). If, each time the list is presented, an IAR is generated, the activation level of the IAR should become higher as the number of presentations increases from one to three, resulting in faster responses to the critical lures. Our conclusion that an IAR model is insufficient to account for the decreasing RT with the increasing presentation frequency is consistent with those in other studies (Benjamin, 2001; McDermott \& Watson, 2001; Seamon et al., 2002). Again, the strength of false memory decreases even when the information is still judged as old. Third, our result has confirmed that when the encoding time is long enough, more presentations lead to weaker false memory. Thus, we provided converging evidence by using RT for several findings in the literature that showed a negative effect of presentation repetition on false memory (see Seamon et al., 2002).

Another planned comparison was between the false alarm RT for the critical nonpresented words and the hit RT for the list words. An ANOVA with presentation fre- 


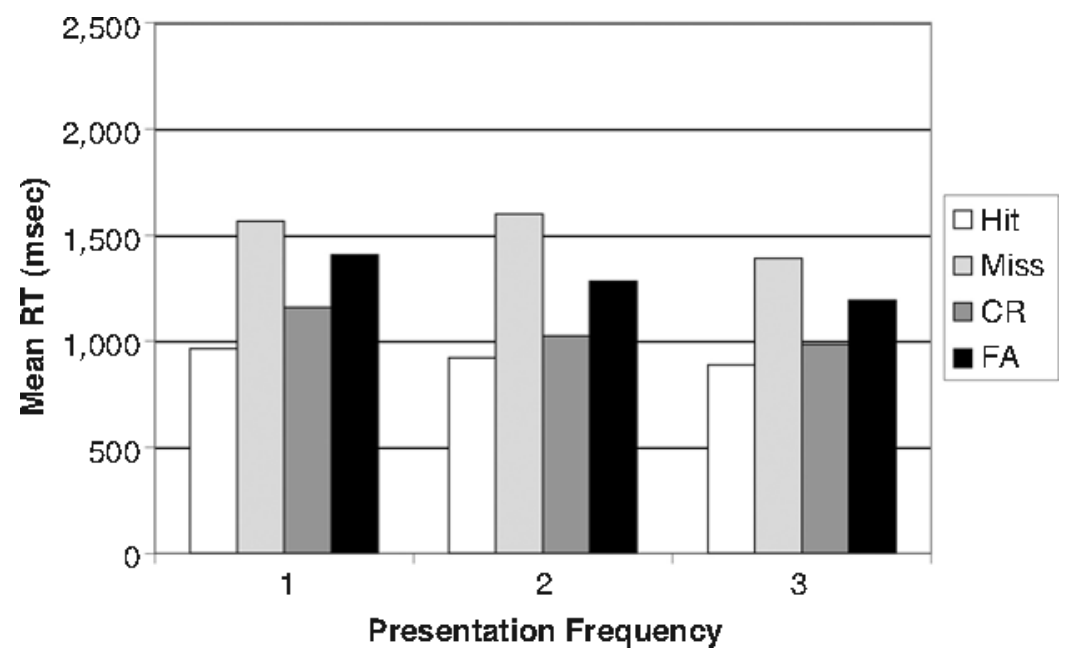

Figure 2. Mean reaction times (RTs, in milliseconds) as a function of presentation frequency and response category for the noncritical words in Experiment 1 (CR, correct rejection; FA, false alarm).

quency as a between-subjects factor and word type (critical nonpresented vs. list words) as a within-subjects factor showed that the presentation frequency main effect was not significant buT that both the word type main effect [mean of false alarms to critical nonpresented words $=$ $1,325 \mathrm{msec}$, and mean of hits to list words $=927 \mathrm{msec}$; $\left.F(1,112)=45.93, M S_{\mathrm{e}}=216,916\right]$ and the presentation frequency $\times$ word type interaction $[F(2,112)=3.86$, $\left.M S_{\mathrm{e}}=216,916\right]$ were significant. This indicated that the speed of false positive recognition (false memory) was slower than the speed of accurate positive recognition of the list words (veridical memory) and that the strength of the former decreased but that of the latter increased in a continuous manner with presentation frequency.

In addition to the specific planned ANOVAs, an overall ANOVA on RT was conducted, using presentation frequency as a between-subjects factor and word type (critical vs. noncritical words) and response category (hit, miss, correct rejection, and false alarm) as withinsubjects factors. Results showed that the presentation frequency main effect was not significant, with the mean RT of presentation frequency 1,2 , and 3 condition being $1,321,1,242$, and $1,171 \mathrm{msec}$, respectively $[F(2,131)=$ $\left.1.23, M S_{\mathrm{e}}=1,055,456, p>.05\right]$. But the word type main effect was significant $\left[F(1,131)=25.36, M S_{\mathrm{e}}=221,142\right]$, with the mean RT for the critical words $(1,286 \mathrm{msec})$ longer than that for the noncritical words $(1,222 \mathrm{msec})$. This suggested that the critical words did not receive less processing overall than the list words and that the participants might not always have been led by the high familiarity of the critical words into making a fast response. Thus, although the false alarm rate for the critical words was very high, the cause of the high error rate did not seem to be a faster, primarily familiarity-based processing mode for the critical words, as opposed to a slower, recollection-based processing mechanism for the noncritical words.

The response category main effect was also significant $\left[F(3,388)=47.96, M S_{\mathrm{e}}=323,602\right]$. A Newman-Keuls test showed that the mean RT of misses $(1,619 \mathrm{msec})$ was significantly longer than those of the false alarms $(1,360 \mathrm{msec})$ and correct rejections $(1,279 \mathrm{msec}$; with the latter two not significantly different from each other) and that the latter two were significantly longer than that of hits $(910 \mathrm{msec})$. This effect has an important implication. It can be examined analytically within the old and the new categories separately. Within the old category, the hit response $(910 \mathrm{msec}$ ) was significantly faster than the false alarm response $(1,360 \mathrm{msec})$, and similarly, within the new category, the correct rejection response $(1,279 \mathrm{msec})$ was significantly faster than the miss response $(1,619 \mathrm{msec})$. This suggests that response speed is sensitive to a second level of difference that exists in the quality or process of the memories within the category recognized as either old or new. The common pattern shown across the two response categories is that the correct responses (hits and correct rejections) are associated with shorter RTs and the incorrect responses (misses and false alarms) with longer RTs. Thus, not only is the speed of true memory (hits) faster than that of the false memory (false alarms), but also the speed of true nonmemory (correct rejections) is faster than the speed of false nonmemory (misses).

The word type $\times$ response category interaction was significant $\left[F(3,241)=15.58, M S_{\mathrm{e}}=242,050\right]$. The interaction derived from the fact (compare Figure 1 with Figure 2) that for the critical nonpresented words, correct rejections took longer than false alarms, whereas for the counterpart of the noncritical words, the reverse was true. This pattern of RT means (i.e., the interaction) sup- 
ports the assumption that the critical nonpresented words have higher familiarity value than the noncritical distractor words. Assume that items that fall far from the decision criterion yield shorter RTs and that those that fall close to the criterion yield longer RTs. The faster speed associated with the old responses and the slower speed associated with the new responses for the critical nonpresented words suggest that items exceeding the criterion fall far above it, whereas items falling below the criterion fall close to the criterion. The reverse was the case for the noncritical counterpart. The word type $\times$ response category $\times$ presentation frequency three-way interaction was significant $\left[F(6,241)=2.30, M S_{\mathrm{e}}=242,050\right]$.

Analysis of accuracy data. The percentages of hits, misses, correct rejections, and false alarms for Experiments 1 and 2 are presented in Table 1.

We expected that the false alarm rate for the critical words should also decrease with presentation frequency. An ANOVA on the false alarm rate for the critical words showed that presentation frequency produced a significant effect $\left[F(2,131)=4.88, M S_{\mathrm{e}}=0.088\right]$. A Newman-Keuls test showed that the mean false alarm rate of the threepresentation condition (.37) was significantly lower than the mean false alarm rate of the one-presentation condition (.57), with the mean false alarm rate of the twopresentation condition (.48) ranked between these two values, but not significantly different from either of these two values. Thus, the false alarm measure of the effect of presentation frequency on false memory was consistent with the RT measure, although the RT measure further suggested that the strength of false memory might have decreased in a continuous manner before a response category change took place.

An overall ANOVA using $A^{\prime}$ as a dependent measure of sensitivity, word type as a within-subjects factor, and presentation frequency as a between-subjects factor was conducted. $A^{\prime}$ is a nonparametric measure of sensitivity, which can range between 0 and 1 , with .5 indicating the chance level and larger values indicating greater sensitivity. ${ }^{7}$ Hit or false alarm rates equal to 0 or 1 were adjusted by adding .05 to or subtracting .05 from each, respectively. This analysis showed, not surprisingly, that sensitivity for the critical words was significantly lower than that for the noncritical words $[F(1,131)=307.31$,

Table 1

Proportion of Each Response Category for the Critical and Noncritical Words for Experiment 1 and Experiment 2

\begin{tabular}{|c|c|c|c|c|c|c|c|c|}
\hline \multirow[b]{2}{*}{ Words } & \multicolumn{2}{|c|}{ Hit } & \multicolumn{2}{|c|}{ Miss } & \multicolumn{2}{|c|}{$\mathrm{CR}$} & \multicolumn{2}{|c|}{ FA } \\
\hline & $M$ & $S D$ & $M$ & $S D$ & $M$ & $S D$ & $\bar{M}$ & $S D$ \\
\hline \multicolumn{9}{|c|}{ Experiment 1} \\
\hline Critical & .96 & .20 & .04 & .20 & .52 & .50 & .48 & .50 \\
\hline Noncritical & .92 & .26 & .08 & .26 & .91 & .28 & .9 & .28 \\
\hline \multicolumn{9}{|c|}{ Experiment 2} \\
\hline Critical & .94 & .23 & .06 & .23 & .51 & .50 & .49 & .50 \\
\hline Noncritical & .92 & .26 & .08 & .26 & .90 & .30 & .10 & .30 \\
\hline
\end{tabular}

Note-CR, correct rejection; FA, false alarm. The sum of proportions of hits and misses $=1$; the sum of proportions of CRs and FAs also $=1$.
$\left.M S_{\mathrm{e}}=.008\right]$, with the mean $A^{\prime}$ of the critical words being .64 and that of the noncritical words .83. This result was consistent with Westerberg and Marsolek's (2003) finding. The presentation frequency main effect was also significant $\left[F(2,131)=10.97, M S_{\mathrm{e}}=0.018\right]$. A NewmanKeuls test indicated that the mean $A^{\prime}$ for the onepresentation condition (.69) was significantly lower than those for the two-presentation condition (.75) and the three-presentation condition (.77), with the latter two means not significantly different from each other. The word type $\times$ presentation frequency interaction was not significant. Thus, sensitivity for both types of words increased as presentation frequency increased from 1 to 2 , but a further increase in sensitivity of .2 (.75 vs. .77) as presentation frequency increased from 2 to 3 did not reach significance. Therefore, the sensitivity results were consistent with the RT results, in that critical words are associated with both longer RTs and lower sensitivity. Hence, the accuracy difference between the critical and the noncritical words cannot be attributed to a speed-accuracy tradeoff between these two types of words.

Again, we have found no evidence that a familiaritybased or a fluency-based heuristic plays a more important role for the critical words than for the list words. In the General Discussion section, we will suggest a possible mechanism causing both longer RTs and lower accuracy for the critical nonpresented words than for the list words.

\section{EXPERIMENT 2}

The primary purpose of Experiment 2 was to determine whether participants were conscious of the differences in the memory process between the accurate and the false recognitions that was reflected in the RTs found in Experiment 1. The common finding in the literature where a remember versus a know judgment was made for the words recognized as old has been that the conscious experiences for these two types of recognition are fairly alike (Gallo et al., 2001; Payne et al., 1996; Roediger \& McDermott, 1995). However, the results of Experiment 1 demonstrated that when RT was used as the dependent measure, a consistent difference between accurate and false recognition was evidenced. Can the reason why the difference is not clearly and consistently reflected in a remember/know verbal report be that only two categories of rating are used? In Experiment 2, we used a four-category confidence judgment for acceptance and rejection responses. For each positive or negative recognition, the participants gave a confidence rating on a 4-point scale. It is possible that when the number of categories for the conscious judgment is increased, the underlying continuously changing experiences can be more accurately reflected in the rating. Another purpose for Experiment 2 was to replicate the results of Experiment 1.

\section{Method}

Participants. One hundred forty-seven undergraduate psychology students participated in the experiment, 49 in each of the three presentation frequency conditions, for extra course credit or for $\$ 7$. 


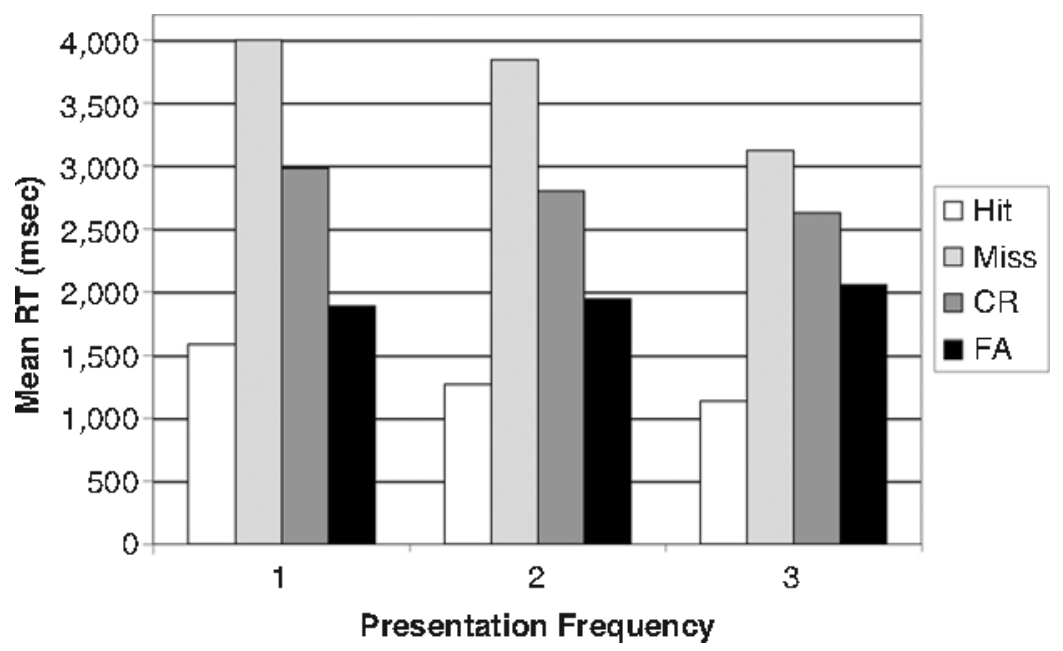

Figure 3. Mean reaction times (RTs, in milliseconds) as a function of presentation frequency and response category for the critical words in Experiment 2 (CR, correct rejection; FA, false alarm).

The data of 1 participant in the three-presentation condition showed that he or she pressed the yes/no key at random and were excluded from analysis. All of the participants had English as their native language.

Materials and Design. The materials and design were the same as those in Experiment 1, except that the participants made a confidence rating on a 4-point scale following each recognition judgment on the probe word.

Procedure. The procedure was the same as that in Experiment 1, except that the participants were prompted for confidence ratings on their responses to the probe words right after they had made yes/no recognition decisions for the words. The screen prompting for a confidence rating came up after the participants had pressed the yes/no response key. There was a 1-sec blank screen between the pressing of the yes/no key and the onset of the confidence-rating screen. For the confidence rating, the participants typed in a number from 1 to 4 on the numeric keypad to indicate how confident they were about their recognition decision, with 1 meaning not confident at all, 2 meaning somewhat confident, 3 meaning highly confident, and 4 meaning absolutely sure. A 1-sec blank screen was shown between the pressing of the number key and the onset of the next probe word.

\section{Results and Discussion}

Analysis of RT data. RTs that were equal to zero or $15,000 \mathrm{msec}$ or longer were excluded from analysis. These trials made up $0.07 \%$ of the data. Mean RTs as a function of presentation condition and response category are presented in Figure 3 for the critical words and in Figure 4 for the noncritical words.

The overall mean RT in Experiment $2(2,069 \mathrm{msec})$ was longer than that in Experiment 1 (1,249 $\mathrm{msec})$. This difference might have been caused by the fact that the confidence rating following the recognition judgment made the whole operation cognitively more complicated (e.g., each trial required the transition from one type of judgment to another) or that the participants might have tried to gauge their own confidence level while reaching a yes/no decision, hence slowing down the overall speed of performance. The planned ANOVA on the RTs for the critical words showed that the mean RT for hits to the critical words $(1,332 \mathrm{msec})$ was significantly shorter than that for false alarms $[2,089 \mathrm{msec} ; F(1,118)=38.20$, $\left.M S_{\mathrm{e}}=993,708\right]$, replicating the results in Experiment 1 . The interaction between presentation frequency and response category was also significant $[F(2,118)=4.38$, $\left.M S_{\mathrm{e}}=993,708\right]$, again replicating the results in Experiment 1 and indicating that repetition of presentations speeded up the hit responses but slowed down the false alarm responses (see Figure 3). Thus, although the overall RT was longer in Experiment 2 than in Experiment 1, the first crucial result was replicated.

Another planned comparison conducted was between the RT for the false alarms to the critical nonpresented words and the RT for the hits to the list words. The presentation frequency main effect was not significant. The word type main effect (mean of the critical nonpresented words $=2,089 \mathrm{msec}$, mean of the hits to list words $=$ $1,336 \mathrm{msec})$ was significant $\left[F(1,118)=36.69, M S_{\mathrm{e}}=\right.$ $929,590]$, indicating that the response speed for hits to the list words (veridical memory) was faster than that for false alarms to the critical nonpresented words (false memory). The presentation frequency $\times$ word type interaction was also significant $\left[F(2,118)=3.45, M S_{\mathrm{e}}=929,590\right]$, indicating that there was a slight trend for the RT for the false alarms to the critical nonpresented words to increase and a clear trend for the RT for the hits to the list words to decrease as presentation frequency increased (see Figures 3 and 4). Again, the interaction suggests that memory strength changes continuously within the same category of memory before a discrete category change takes place.

An overall ANOVA on RT showed that the main effect of presentation frequency was marginally significant $\left[F(2,143)=2.32, M S_{\mathrm{e}}=2,968,067, p=.10\right]$. A Newman-Keuls test showed that the mean RT in the onepresentation condition $(2,284 \mathrm{msec})$ was significantly 


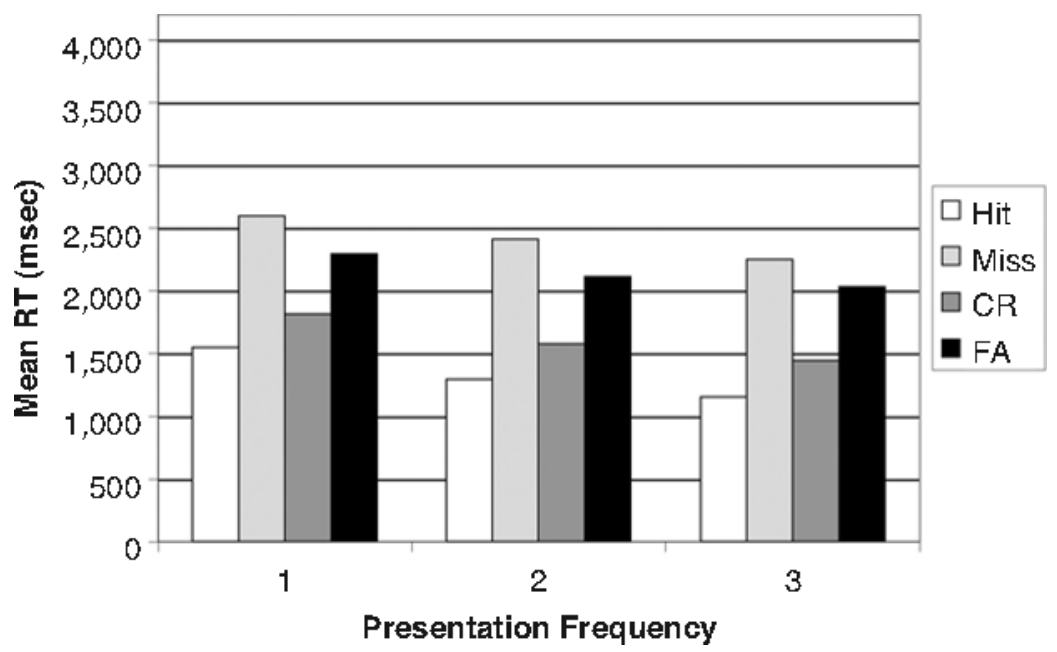

Figure 4. Mean reaction times (RTs, in milliseconds) as a function of presentation frequency and response category for the noncritical words in Experiment 2 (CR, correct rejection; FA, false alarm).

longer than those in the two-presentation condition $(2,012 \mathrm{msec})$ and the three-presentation condition $(1,903 \mathrm{msec})$, with the latter two being not significantly different from each other. This result did not completely replicate that in Experiment 1, in which the mean RTs in the three presentation conditions were not significantly different from one another. The lack of difference in Experiment 1 might have been caused by the overall very low RT in Experiment 1 (the mean RT in the onepresentation condition, the longest mean RT, was only $1,321 \mathrm{msec})$. The main effect of word type was significant $\left[F(1,143)=35.31, M S_{\mathrm{e}}=653,340\right]$, with the mean RT for the critical words being $2,152 \mathrm{msec}$ and that for the noncritical words $2,009 \mathrm{msec}$. Also significant was the main effect of response category $[F(3,421)=65.90$, $\left.M S_{\mathrm{e}}=1,248,273\right]$, with the mean RT for misses being the longest $(2,883 \mathrm{msec})$, which was significantly longer than that for the false alarms $(2,259 \mathrm{msec})$ and correct rejections $(2,168 \mathrm{msec}$; with these two mean RTs being not significantly different from each other), which were both in turn significantly longer than that for the hits $(1,334 \mathrm{msec})$. Thus, the pattern of the response category effect exactly replicated that in Experiment 1, indicating that the further distinction between the true and the false memories within the old and the new categories of items is a robust one. Finally, the word type $\times$ response category interaction was significant $[F(3,262)=28.74$, $\left.M S_{\mathrm{e}}=891,647\right]$, as was the word type $\times$ response category $\times$ presentation frequency three-way interaction $\left[F(6,262)=2.65, M S_{\mathrm{e}}=891,647\right]$. Thus, the pattern of the RT results in Experiment 2 replicated that in Experiment 1 in most of the major aspects of the results.

Analysis of accuracy data. The proportions of hits, misses, correct rejections, and false alarms in Experiment 2 are presented in Table 1 . The planned analysis on the false alarm rate for the critical words also very much replicated the results in Experiment 1. The main effect of presentation frequency was significant $[F(2,143)=$ $\left.3.32, M S_{\mathrm{e}}=0.107\right]$. A Newman-Keuls test showed that the mean false alarm rate in the three-presentation condition (.42) was significantly lower than that in the onepresentation condition (.59), with the size of the mean false alarm rate in the two-presentation condition (.48) ranked in between them, but not significantly different from either one of these. Thus, the repetition of presentation of list words decreased the proportion of the false positive recognition of the critical nonpresented words.

An overall ANOVA on $A^{\prime}$, with presentation frequency as a between-subjects factor and word type as a withinsubjects factor, showed that the presentation frequency main effect was significant $\left[F(2,143)=12.88, M S_{\mathrm{e}}=\right.$ 0.020 ], with the mean $A^{\prime}$ in the one-presentation condition (.67) significantly smaller than those in the twopresentation (.76) and three-presentation (.77) conditions and with the latter two mean $A^{\prime}$ 's not significantly different from each other. The word type main effect was highly significant $\left[F(1,143)=279.27, M S_{\mathrm{e}}=0.01\right]$, with the mean $A^{\prime}$ for the critical words being .63 and that for the noncritical words being .83. The presentation frequency $\times$ word type interaction was not significant. Thus, both the test results and the magnitudes of the mean $A$ 's in Experiment 2 closely replicated their counterparts in Experiment 1.

Analysis of confidence rating. Mean confidence ratings as a function of presentation frequency and response category are presented in Figure 5 for the critical words and in Figure 6 for the noncritical words.

A correlation between RT and confidence rating was computed on a trial-by-trial basis to determine whether the fluency, or lack thereof, in the responses the participants made was reflected, at least to some extent, in their confidence ratings. For the critical words, the correlation between RT and confidence rating was $r=-.45$, which was highly significant, and for the noncritical word, $r=$ 


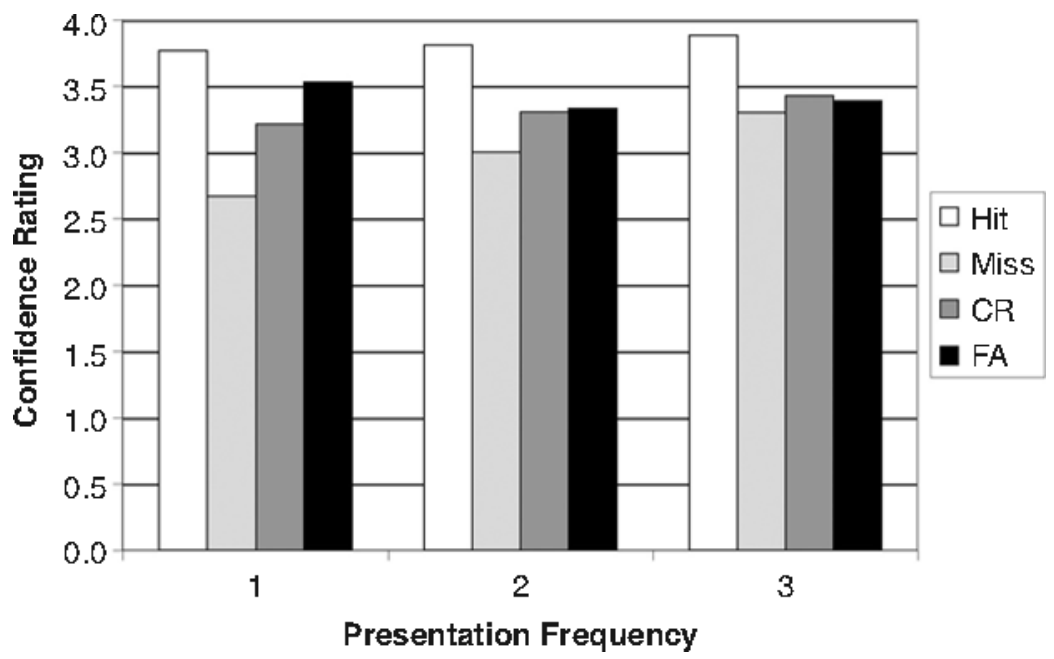

Figure 5. Mean confidence ratings as a function of presentation frequency and response category for the critical words in Experiment 2 (CR, correct rejection; FA, false alarm).

-.39 , which also was highly significant. For the two types of words combined, $r=-.39$, which again was highly significant. Thus, in general, a slower response was associated with less confidence, and vice versa.

The planned analysis on the hits and false alarms for the critical words showed that the main effect of response category was significant $[\mathrm{F}(1,118) 557.80$, MSe 5 0.248 , with the mean confidence rating for hits being 3.83 and that for false alarms 3.35. This effect was consistent with the corresponding RT effect in both experiments, in that a shorter RT was associated with a higher confidence rating. The main effect of presentation frequency was not significant. A possible explanation for this lack of a main effect of presentation frequency on confidence rating may be that because presentation frequency was a between-subjects factor, the participants could not compare their confidence levels across the presentation conditions. They might have had a tendency to use the whole range of the confidence scale anyway, regardless of the presentation frequency (Parducci, 1984). The presentation frequency $\times$ response category interaction was marginally significant $[F(2,118)=2.26, p=$ .10]. There was some indication that the confidence level for hits increased but that for false alarms slightly decreased across the three presentation frequencies.

The second planned comparison was between the false alarms to the critical nonpresented words (false memory) and the hits to the list words (veridical memory), using pre-

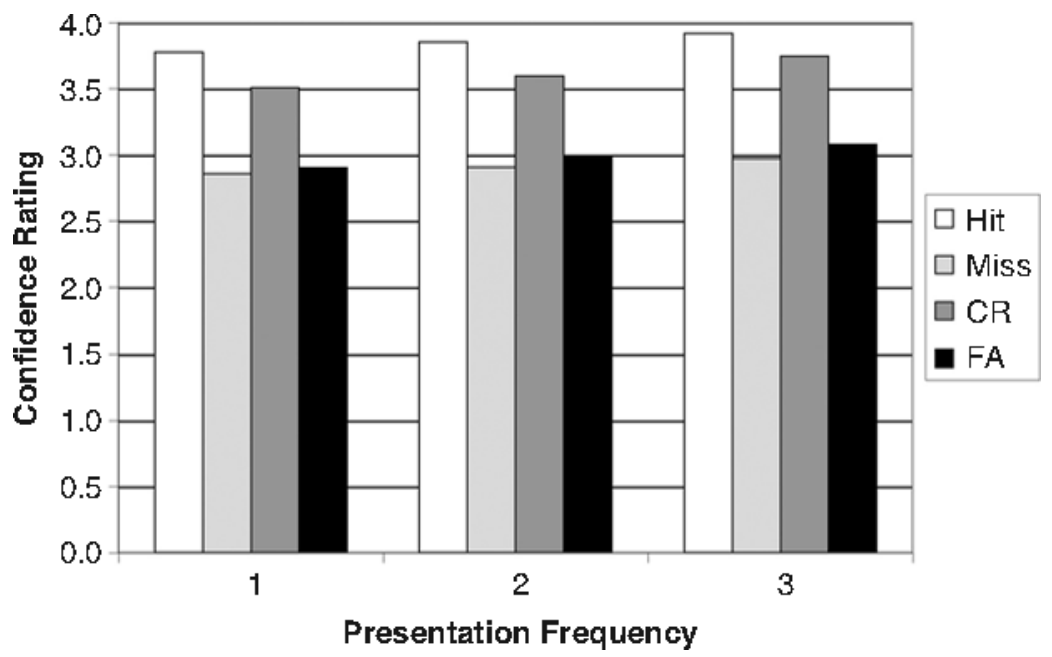

Figure 6. Mean confidence ratings as a function of presentation frequency and response category for the noncritical words in Experiment 2 (CR, correct rejection; FA, false alarm). 
sentation frequency as a between-subjects factor and word type as a within-subjects factor. Again, the presentation frequency main effect was not significant. The word type main effect was significant $\left[F(1,118)=62.93, M S_{\mathrm{e}}=\right.$ $0.239]$, with the mean confidence rating for the false alarm to the critical nonpresented words being 3.35 and that for hits to the list words being 3.84. This indicated that the participants had higher confidence in veridical recognition of the list words than in false positive recognition of the critical nonpresented words. The presentation frequency $\times$ word type interaction was marginally significant $\left[F(2,118)=2.80, M S_{\mathrm{e}}=0.239, p=.06\right]$, indicating that confidence for the critical nonpresented words seems to have decreased slightly from the one-presentation to the two-presentation conditions, whereas it increased for hits to the list words (see Figures 5 and 6). Thus, two converging pieces of evidence, RTs and confidence ratings, have clearly indicated that accurate memory and false memory are different and that the difference is captured both in the on-line RT measure and in the postresponse phenomenological judgment.

The confidence rating result supports our hypothesis that the remember rating that participants often give to false memory to the extent comparable to accurate memory may have resulted either from the rating's having only two categories or from a long delay between studying and testing. In fact, in our 4-point confidence rating scale, both types of memories were rated in the range of 3 to 4 . If only two categories (e.g., remember and know) had been used, the two ratings would both have fallen in the remember category.

An overall ANOVA on confidence rating, using presentation frequency as a between-subjects factor and word type and response category as within-subjects factors, showed that the presentation frequency main effect was again not significant but the response category main effect was $\left[F(3,421)=108.49, M S_{\mathrm{e}}=0.252\right]$, with hits being given the highest confidence rating (mean rating $=$ 3.83 ), correct rejections the second highest rating (3.46), false alarms the third highest rating (3.14), and misses the lowest rating (2.96). A Newman-Keuls test showed that each mean was significantly different from the other. Note that the rank order of the confidence ratings for the four response categories was the exact reverse of that of the RTs. Again, consistent with the RT results, the participants were capable of further distinguishing the two subcategories of memories within the old and the new categories, respectively, and had higher confidence for correct responses (hits and correct rejections) than for incorrect responses (false alarms and misses). The word type $\times$ response category interaction was also significant $[F(3,262)=23.33$, $\left.M S_{\mathrm{e}}=0.181\right]$. The interaction stemmed from the different confidence-rating rankings of the response categories across the two types of words (see Figures 5 and 6 ). For example, for the critical words, the false alarms received confidence ratings either higher (in the one-presentation condition) or, at least, no lower than the misses and cor- rect rejections (in the two- and three-presentation conditions). For the noncritical words, on the other hand, the confidence rating for the false alarms was always lower than that for the correct rejections. These confidencerating patterns were again generally consistent with the RT pattern, in that faster responses tended to be associated with higher confidence ratings and vice versa.

One exception to this confidence/RT correspondence was that the word type main effect on confidence rating was not significant, with the mean confidence rating for the critical words being 3.47 and that for the noncritical words being 3.35. On the other hand, the word type main effect on RT was highly significant, with the mean RT for the critical words being $2,152 \mathrm{msec}$, and that for the noncritical words being 2,009 msec. But since the correlation between the two measures was not perfect, the finding of some degree of dissociation between the two measures was not surprising.

\section{EXPERIMENT 3}

An important question to be asked is whether the RT difference between the false positive recognition and the veridical recognition we obtained in Experiments 1 and 2 were related to the relatively low false alarm rates we obtained for the critical nonpresented words (.48 and .49), as compared with the typical false recognition rates of over .60 (Stadler, Roediger, \& McDermott, 1999) or .70 (Roediger \& McDermott, 1995) in studies in which the DRM paradigm has been used. In other words, can the "false recognition" we studied be different in nature from what other false memory researchers have reported in the literature? We suspect that there are two potential sources for the different rates of false alarms to the critical nonpresented words found in our data and in the previously reported results. The first one is the composition of the word list used at study and in the recognition test. Because of the expansion of our word list from 15 (in a typical DRM paradigm) to 30 words, the association strength between the words in our study list might have been weakened, resulting in a lower backward association strength (Roediger \& McDermott, 1995) for the critical nonpresented word in each list. In addition, in the typical DRM paradigm, both related and unrelated words are used as distractors (in Experiment 2 of Roediger and McDermott's study, all the distractor words, but not the critical nonpresented words, were unrelated), whereas in Experiments 1 and 2, only related words were used as distractors. Finally, unlike a typical DRM procedure in which none of the critical words is presented, in Experiments 1 and 2, half of the critical words were presented for study. Both of these two changes can raise the decision criterion of the judgment (M. B. Miller \& Wolford, 1999), leading to a lower false alarm rate. A second potential source of the false alarm rate difference is the retention size (the number of lists studied before taking the recognition test). In a typical DRM recognition experiment, the recognition test is 
given after a large number of lists (e.g., 6 lists in Experiment 1 and 12 lists in Experiment 2 in Roediger \& McDermott's, 1995, study) have been studied (or studied and recalled). In Experiments 1 and 2, we had the participants study one list of words and be tested on that list, and so on, resulting in a retention size of only one list.

Therefore, the purpose of Experiment 3 was twofold. First, it was to answer the question of whether and how study and test list composition might affect the false alarm rate for critical nonpresented words and the RT difference between false alarms to critical nonpresented words and hits to list words. Second, it was designed to determine whether retention size would affect these two measures. Of course, the first question has to be answered by comparing the results of Experiments 1 and 2 with those in Experiment 3. The second question can be answered within Experiment 3, since retention size was varied in this experiment. A secondary question this experiment will answer is whether list composition and retention size may affect different measures. For example, could one factor affect the false alarm rate and the other the RT difference between false alarm responses to critical nonpresented words and hits to list words?

\section{Method}

Participants. A total of 293 undergraduate students participated in this experiment for extra course credit -48 in the 1-list, 40 in the 2-list, 43 in the 3-list, 41 in the 4-list, 41 in the 6-list, and 80 in the $12-$ list retention size conditions. All the participants had English as their native language.

Materials and Design. Of the 24 lists of words (of 15 words each) in Roediger and McDermott (1995), the 12 that, according to Stadler et al.'s (1999) DRM list norm study, elicited the highest false alarm rates to critical nonpresented words were used in this experiment. The procedures by which the list words were presented for study, the distractor words were selected, and the test words were presented were all modeled after Roediger and McDermott's Experiment 2 as closely as possible. The only marked deviation in this experiment from the DRM paradigm was that we varied the number of lists of words (retention size) the participants learned before they were given the recognition test (in the standard DRM paradigm, participants learned a given number of word lists, typically from 6, as in Experiment 1, to 16, as in Experiment 2 of Roediger and McDermott's study, before they took the recognition test). The number of lists the participants learned in the present experiment before the recognition test was varied between participants. Thus, the participants learned 1, 2, 3, 4, 6, or 12 lists of words before taking the recognition test. Therefore, those in the 1-list condition repeated the study-test cycle 12 times, those in the 2-list condition repeated it 6 times, those in the 3-list condition repeated it 4 times, those in the 4-list condition repeated it 3 times, those in the 6-list condition repeated it 2 times, and those in the 12-list condition underwent the study-test cycle only once.

In the one-list condition, the test words for a studied list were composed of a total of 6 words, of which one was the critical nonpresented word for that particular list, 1 word was selected from Position 1, 1 word from Position 8, and 1 word from Position 10 of the studied list; the remaining 2 words were randomly chosen from a set of 24 nonpresented, or distractor, words (consisting of six critical words for six nonstudied lists, and 18 other distractor words, 3 from each of the six nonstudied lists, 1 word from Position 1, 1 from Position 8 , and 1 from Position 10 of each of the six lists). Thus, in this design, all the nonpresented distractor words, but not the critical nonpresented words, for the target lists were unrelated words. This design was modeled after Experiment 2 in Roediger and McDermott's (1995) study and was expected to maximize the false alarm rate for the critical nonpresented words.

The list words were presented one at a time in the same order for each participant as these words were ordered in each of the lists in Roediger and McDermott's (1995) study (Appendix, p. 814; i.e., the words were ordered according to the descending association value, as the authors indicated). The test words were presented for recognition in a new random order for each participant. Where the retention size was larger than one list, the test words for each list were selected in the same way as that in the 1-list condition. The pooled set of test words for these lists was presented for recognition in a new random order for each participant. The largest set of the test words (the 12-list condition) had 72 words, of which 12 were critical nonpresented words of the target lists, 36 were list words, and 24 were unrelated distractor words, of which 6 were the critical words for 6 nonpresented lists and 18 were the $1 \mathrm{st}$, 8th, and 10th words from the 6 nonpresented lists. Thus, the design of the 6-list and 12-list conditions was essentially the same as a typical DRM paradigm recognition task.

Procedure. The procedure for presenting words for study and testing was the same as that in Experiments 1 and 2, except that at the end of presenting a list of words, the participants could press the Enter key either to present the next list of words for study or to start the 30-sec backward counting before the recognition test, depending on the retention size condition they were in.

\section{Results and discussion}

The same significance criterion as that in Experiments 1 and 2 was used in this experiment unless otherwise noted. An error in the program used for the first 40 participants in the 12-list retention size condition caused four words to be presented for recognition twice, once correctly as one critical nonpresented word and three list words, and once incorrectly as unrelated words. The data associated with these eight trials were excluded from analysis. The pattern of means from the remaining data of these 40 participants was compared with that of the remaining participants' and was found to be the same.

Analysis of accuracy data. Because the false alarm rate obtained for the critical nonpresented words in this experiment is a crucial piece of information for the interpretation of the RT and confidence-rating data, we examined the false alarm rate for the critical nonpresented words first. The mean false alarm rate and the correct rejection rate for the critical nonpresented words as well as the hit, miss, correct rejection, and false alarm rates for the list and the distractor words are presented as a function of retention size in Table 2 .

As can be seen, the false alarm rate for the critical nonpresented words ranged from .72 to .78 , which closely approximated the magnitudes typically reported in studies in which the DRM recognition paradigm has been used (Roediger \& McDermott, 1995, obtained a false alarm rate for the critical nonpresented words of .81 for the studyplus-recall condition and .72 for the study-plus-arithmeticproblem condition, and Stadler et al., 1999, obtained a false alarm range of .84 to .27 for the critical nonpresented words, so ours is above average in this range). Thus, when the test word lists were constructed according to the DRM 
Table 2

Proportion of Each Response Category for the Critical and Noncritical Words of Each Retention Size of Experiment 3

\begin{tabular}{|c|c|c|c|c|c|c|c|c|c|}
\hline \multirow{2}{*}{$\begin{array}{c}\text { Retention } \\
\text { Size }\end{array}$} & \multirow[b]{2}{*}{ Words } & \multicolumn{2}{|c|}{ Hit } & \multicolumn{2}{|c|}{ Miss } & \multicolumn{2}{|c|}{$\mathrm{CR}$} & \multicolumn{2}{|c|}{ FA } \\
\hline & & $P$ & $S D$ & $P$ & $S D$ & $P$ & $S D$ & $P$ & $S D$ \\
\hline \multirow[t]{2}{*}{1 list } & Critical & - & & . & & & & 75 & .43 \\
\hline & & .90 & .30 & .10 & .30 & .97 & & 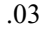 & .1 \\
\hline \multirow[t]{2}{*}{2 lists } & Criti & - & & - & & .22 & .41 & .78 & .41 \\
\hline & & .87 & .34 & .13 & .34 & .96 & .2 & .04 & .20 \\
\hline \multirow[t]{2}{*}{3 lists } & Crit & - & & - & & .26 & .44 & .74 & .44 \\
\hline & & .85 & .36 & .15 & .36 & .95 & .22 & .05 & .22 \\
\hline \multirow[t]{2}{*}{4 lists } & & - & & - & & .22 & .4 & .78 & .41 \\
\hline & & .85 & .3 & .15 & .34 & .94 & .2 & .06 & .24 \\
\hline \multirow[t]{2}{*}{6 lists } & & - & & - & & .28 & .45 & .72 & .45 \\
\hline & $\mathrm{No}$ & .80 & .40 & .20 & .40 & .92 & .27 & .08 & .27 \\
\hline \multirow{2}{*}{12 lists } & & - & & - & & .23 & .4 & .77 & .42 \\
\hline & Noncritical & .78 & .41 & .22 & .41 & .87 & .34 & .13 & .34 \\
\hline
\end{tabular}

Note-CR, correct rejection; FA, false alarm. The sum of proportions of hits and misses $=1$; the sum of proportions of CRs and FAs also $=1$. Since no critical words were presented, there were no hits or misses for the critical words.

paradigm, false alarm rates for the critical nonpresented words comparable to those in other studies were obtained. An ANOVA on the false alarm rate 8 for the critical nonpresented words, using retention size as a between-subjects factor, showed no significant effect of retention size $(F<1)$. Thus, the false alarm rates of the critical nonpresented words seemed to be determined by the word composition of the study and/or test lists, rather than by retention size. On the other hand, when an ANOVA was performed on the $A^{\prime}$ measure of the noncritical words (list words and distractors), the effect of retention size was significant $[F(5,288)=14.85$, $\left.M S_{\mathrm{e}}=0.012\right]$. The order of the mean $A$ 's and the results of the post hoc Newman-Keuls test are presented in Table 3.

The results showed that as the retention size increased, the sensitivity decreased in an orderly manner, although the false alarm rates for the critical nonpresented words did not seem to be affected in any systematic way by the retention size.

Analysis of RT data. The outliers were excluded from analysis in the same way as in Experiments 1 and 2. The excluded trials made up $0.5 \%$ of the data. Three ANOVAs were conducted to make three planned comparisons. The first comparison was the most crucial one, in which the mean RT for the false alarms to the critical nonpresented words was contrasted with that for the hits to the list

Table 3

Mean $\boldsymbol{A}^{\prime}$ Measures of the Noncritical Words as a Function of Retention Size

\begin{tabular}{|c|c|c|}
\hline Retention Size & Mean & NK Grouping \\
\hline 1 list & .870 & A \\
\hline 2 lists & .821 & B \\
\hline 3 lists & .791 & B \\
\hline 4 lists & .789 & B \\
\hline 6 lists & .756 & $\mathrm{D}$ \\
\hline 12 lists & .713 & D \\
\hline
\end{tabular}

Note-NK, the Newman-Keuls test. Means labeled by the same letter are not significantly different from one another. words. The second comparison was between the mean RT for the hits to the list words and that for the false alarms to the distractor words. The third ANOVA compared the mean RT for the misses to the list words with that for the correct rejections to the distractor words. Mean RTs as a function of response category and retention size are shown in Table 4A.

The first ANOVA conducted used response category (false alarms to the critical nonpresented words vs. hits to the list words) as a within-subjects factor, and retention size $(1,2,3,4,6$, and 12 lists) as a between-subjects factor. The overall mean RT for the false alarms to the critical nonpresented words $(2,170 \mathrm{msec})$ was significantly longer than that for the hits to the list words $(1,864 \mathrm{msec}$; $\left.F(1,285)=50.45, M S_{\mathrm{e}}=323,653\right]$. The main effect of retention size was not significant $\left[F(5,287)=1.20, M S_{\mathrm{e}}=\right.$ $1,105,588]$. The mean RTs in Table 4A seem to indicate that the RT difference between the two categories of responses was diminished when the retention size was increased to 4,6 , and 12 . This observation was confirmed by a significant interaction between response category and retention size $\left[F(5,285)=2.99, M S_{\mathrm{e}}=323,653\right]$. There was also some indication that the RT for the hits to the list words increased as the retention size increased, whereas there was not such a trend for the false alarms to the critical nonpresented words. A linear regression analysis confirmed this impression. ${ }^{9}$ The upward slope $(24.81 \mathrm{msec})$ for the hit RT as a function of retention size was significant $[t(291)=2.70, S E=9.19]$, whereas the downward slope $(-14.53 \mathrm{msec})$ for the false alarm RTs to the critical nonpresented words was not $[t(289)=-1.04, S E=13.92]$. Thus, although retention size affected the RT for the list words, it did not seem to affect the RT for the critical nonpresented words. The results also indicated that the RT difference between the critical nonpresented words and the list words was a function of retention size. Since we also obtained this RT difference in Experiments 1 and 2, we can tentatively conclude that the composition of words in the test lists was not responsible for the crucial RT difference we obtained in this study. It was the single-list retention size that we used in Experiments 1 and 2 that was responsible for the RT difference between the critical nonpresented words and the list words.

The second ANOVA was conducted to compare the RTs for the hits to the list words with the RTs for the false alarms to the distractor words (false positive recognition). Mean RTs as a function of response category and retention size are shown in Table 4A. As was apparent, the mean RT for the false alarms to the distractor words $(3,404 \mathrm{msec})$ was significantly longer than that for the hits to the list words $(1,864 \mathrm{msec})$. The main effect of retention size was not significant $(F<1)$, nor was the response category $\times$ retention size interaction significant. However, it was indicated earlier that the linear upward trend for the hit RT as a function of retention size for the list words was significant $[t(291)=2.70, S E=9.19]$. The same regression analysis showed that the downward trend $(-15.98 \mathrm{msec})$ was not significant for the false 
alarm RT function of the distractor words $(t<1)$. The false alarm rate for the distractor words was very low; therefore, the lack of significance might be due to the low power of the test. The two planned ANOVAs showed that the hit responses to the list words were significantly faster than both the false alarm responses to the critical nonpresented words and the false alarm responses to the distractor words.

The third ANOVA was conducted to compare the RT for the misses to the list words with that for the correct rejections to the distractor words. The mean RTs for these two categories of responses are presented in Table 4A as a function of response category and retention size. The mean RT for misses to the list words $(3,222 \mathrm{msec})$ was significantly longer than that for the correct rejections to the distractor words $(2,081 \mathrm{msec})\left[F(1,268)=261.19, M S_{\mathrm{e}}=\right.$ $720,796]$. The main effect of retention size was not significant $(F<1)$. The response category $\times$ retention size interaction was significant $\left[F(5,268)=4.00, M S_{\mathrm{e}}=\right.$ 720,796]. A linear regression analysis showed that the slope of the mean RT for misses $(-22.24 \mathrm{msec})$ as a function of retention size was not significant $[t(273)=-1.96$, $S E=21.96]$, whereas the slope of the mean RT for correct rejections $(48.25 \mathrm{msec})$ was significant $[t(290)=$ $4.57, S E=10.56]$. Thus, correct rejection of the distractor words took longer as retention size became larger. Also, as the retention size became larger, the difference in RT between the correct and the incorrect new responses narrowed down. The overall picture of the RT data suggested that the correct responses (whether old or new) were faster than the incorrect responses but that this difference tended to narrow down as the retention size increased.
Analysis of confidence rating. The trial by trial correlation between the RT and the confidence rating was -.34 for the critical nonpresented words, -.29 for the noncritical words, and -.30 for the two types of words combined. The correlations for the six retention sizes were $-.38,-.36,-.37,-.33,-.24$, and -.24 for the $1-, 2-, 3-$, 4-, 6-, and 12-list conditions, respectively. All these correlations were highly significant. Thus, as retention size increased, the correlation between RT and confidence rating decreased. The same planned ANOVAs as those conducted for the RT data were conducted for the confidence-rating data. The first ANOVA compared the confidence ratings for the false alarm responses to the critical nonpresented words with those for the hit responses to the list words. Mean confidence ratings as a function of response category and retention size are presented in Table 4B. Note the roughly mirror-image relationship between the RT magnitudes and the confidence-rating values. As is evident in Table 4B, the mean confidence rating for the hits to the list words (3.63) was significantly higher than that for the false alarms to the critical nonpresented words (3.40) $\left[F(1,285)=113.65, M S_{\mathrm{e}}=0.065\right]$. The main effect of retention size was not significant $[F(5,287)=$ $\left.1.33, M S_{\mathrm{e}}=0.260\right]$. However, the response category $\times$ retention size interaction was significant $[F(5,285)=$ $\left.3.58, M S_{\mathrm{e}}=0.065\right]$. Because of the significant interaction, a separate linear regression was conducted on confidence rating as a function of retention size for each response category. The results showed that the downward trend for the false alarms $(-.003)$ was not significant $(t<1)$, whereas that for the hits $(-.016)$ was significant $[t(291)=-3.57, S E=0.005]$. Thus, the pattern

Table 4A

Mean Reaction Times (in Milliseconds) as a Function of Response Category and Retention Size in Experiment 3

\begin{tabular}{|c|c|c|c|c|c|c|c|c|c|c|c|c|}
\hline \multirow[b]{3}{*}{ Response Category } & \multicolumn{12}{|c|}{ Retention Size (Number of Lists) } \\
\hline & \multicolumn{2}{|c|}{1} & \multicolumn{2}{|c|}{2} & \multicolumn{2}{|c|}{3} & \multicolumn{2}{|c|}{4} & \multicolumn{2}{|c|}{6} & \multicolumn{2}{|c|}{12} \\
\hline & $M$ & $S D$ & $M$ & $S D$ & $M$ & $S D$ & $M$ & $S D$ & $M$ & $S D$ & $M$ & $S D$ \\
\hline FAs to distractor word & 3,315 & 1,723 & 3,117 & 2,730 & 3,539 & 2,010 & 3,346 & 2,022 & 2,498 & 2,534 & 2,513 & 2,016 \\
\hline FAs to critical wor & 2,114 & 1,152 & 2,323 & 814 & 2,016 & 829 & 1,834 & 1,306 & 2,147 & 921 & 2,083 & 929 \\
\hline Hits to list words & 1,623 & 443 & 1,841 & 557 & 1,752 & 433 & 1,737 & 415 & 2,111 & 802 & 1,948 & 882 \\
\hline Misses to list words & 3,229 & 1,611 & 3,341 & 1,429 & 2,901 & 1,271 & 2,911 & 1,693 & 3,147 & 1,454 & 2,763 & 1,449 \\
\hline CRs to distractor words & 1,654 & 471 & 1,993 & 677 & 1,977 & 660 & 2,026 & 743 & 2,286 & 973 & 2,319 & 851 \\
\hline
\end{tabular}

Note-FA, false alarm; CR, correct rejection.

Table 4B

Mean Confidence Ratings as a Function of Response Category and Retention Size in Experiment 3

\begin{tabular}{|c|c|c|c|c|c|c|c|c|c|c|c|c|}
\hline \multirow[b]{3}{*}{ Response Category } & \multicolumn{12}{|c|}{ Retention Size (Number of Lists) } \\
\hline & \multicolumn{2}{|c|}{1} & \multicolumn{2}{|c|}{2} & \multicolumn{2}{|c|}{3} & \multicolumn{2}{|c|}{4} & \multicolumn{2}{|c|}{6} & \multicolumn{2}{|c|}{12} \\
\hline & $M$ & $S D$ & $M$ & $S D$ & $M$ & $S D$ & $M$ & $S D$ & $M$ & $S D$ & $M$ & $S D$ \\
\hline FAs to distractor words & 3.04 & 0.47 & 2.78 & 0.82 & 2.43 & 0.90 & 2.65 & 0.94 & 2.81 & 0.89 & 2.38 & 0.84 \\
\hline FAs to critical words & 3.42 & 0.47 & 3.45 & 0.42 & 3.42 & 0.55 & 3.54 & 0.53 & 3.38 & 0.50 & 3.39 & 0.38 \\
\hline Hits to list words & 3.79 & 0.22 & 3.67 & 0.28 & 3.65 & 0.36 & 3.71 & 0.29 & 3.53 & 0.45 & 3.56 & 0.33 \\
\hline Misses to list words & 3.06 & 0.69 & 2.67 & 0.62 & 2.71 & 0.71 & 2.69 & 0.57 & 2.85 & 0.65 & 2.52 & 0.58 \\
\hline CRs to distractor words & 3.77 & 0.28 & 3.51 & 0.44 & 3.30 & 0.57 & 3.25 & 0.63 & 3.25 & 0.61 & 2.91 & 0.59 \\
\hline
\end{tabular}

Note-FA, false alarm; CR, correct rejection. 
of the confidence-rating results closely echoed that of the RT results.

The second ANOVA was conducted to compare the confidence ratings for the hit responses to the list words with those for the false alarm responses to the distractor words. The mean confidence ratings for these two types of responses are presented in Table $4 \mathrm{~B}$ as a function of response category and retention size. The mean confidence rating for the hits to the list words (3.63) was significantly higher than the mean confidence rating for the false alarms to the distractor words $(2.48)[F(1,147)=$ $\left.151.88, M S_{\mathrm{e}}=0.366\right]$. Neither the main effect of retention size $\left[F(5,287)=1.24, M S_{\mathrm{e}}=0.304\right]$ nor the response category $\times$ retention size interaction was significant $(F<1)$. However, a separate regression analysis for the two confidence-rating functions indicated that the hit confidence-rating function had a significant downward trend $(-.016)[t(291)=-3.75, S E=0.005]$, although the false alarm function did not $(t<1)$. Finally, the third ANOVA was conducted to compare the confidence rating for misses to the list words with that for the correct rejections to the distractors. These mean confidence ratings as a function of response category and retention size are presented in Table 4B. The mean confidence rating for correct rejections to the distractor words (3.27) was significantly higher than that for misses to the list words $(2.66)\left[F(1,268)=303.89, M S_{\mathrm{e}}=0.169\right]$. The main effect of retention size was also significant $\left[F(5,287)=10.93, M S_{\mathrm{e}}=0.504\right]$, as was the response category $\times$ retention size interaction $[F(5,268)=4.69$, $\left.M S_{\mathrm{e}}=0.169\right]$. The mean confidence rating for correct rejection as a function of retention size had a greater downward slope $(-.064)$ than did the miss function $(-.031)$. Again, the pattern of these confidence-rating results largely mirrored their counterpart in the RT data.

\section{GENERAL DISCUSSION}

There are several important implications and conclusions from this study. We will discuss each of them below.

More objective and sensitive measures of true/false memory differences. Across the three experiments, the response latency measure has reliably shown that false recognition and veridical recognition are clearly distinguishable. Our RT and confidence-rating results were consistent with the findings in studies in which PET (see Norman \& Schacter, 1997, for a review), P300 (A. R. Miller et al., 2001) and lateralized brain potentials (Fabiani et al., 2000) have been used, with findings of a higher recall or recognition rate for the critical presented words than for the nonpresented words (McDermott, 1997; M. B. Miller \& Wolford, 1999), and with the finding that critical nonpresented words tended to be output at later sequential positions in recall (Payne et al., 1996; Roediger \& McDermott, 1995). The negative correlation between confidence rating and RT indicated that, in general, the participants experienced more confidence in a fast response than in a slow response. The confidence- rating data also indicated that the participants were less confident in the false positive (false memory) and false negative (false nonmemory) responses than in the accurate positive and negative responses. Thus, there is no indication of a dissociation between the RT measure and the confidence rating. However, if we had used a twocategory rating instead of four, both our mean confidence ratings for false recognition of the critical nonpresented words (3.35 in Experiment 2 and 3.40 in Experiment 3) and those for accurate recognition of the list words (3.84 in Experiment 2 and 3.63 in Experiment 3) would have fallen into the same higher category.

A possible explanation for the inconsistent phenomenological reports on false memory. As was noted at the beginning of this article, the research on the phenomenological characteristics of false memory seems to have presented a two-sided picture. One line of research has presented a picture of false memory that is vivid, realistic, and almost indistinguishable from veridical memory (Gallo et al., 2001; Lampinen et al., 1999; Payne et al., 1996; Roediger \& McDermott, 1995; Toglia et al., 1999), and the other a picture indicating the phenomenological differences between the two types of memory (Johnson et al., 1988; Johnson \& Raye, 1981; Mather et al., 1997; Norman \& Schacter, 1997). We suggest several potential sources of the reported discrepancies on the phenomenological experiences of false memory.

The first potential source of the inconsistency may be the subjective nature of the verbal report measure, which makes it rather susceptible to the contextual demand characteristics present in varying degrees across different studies. The delay between experiencing an internal event and rating is also a relevant factor. Retention size (as well as interval) definitely determines how similar the subjective experiences of the true and the false memories can be. The results from Experiment 3 clearly showed that as retention size increases, the gaps in RT, as well as in confidence rating, between true and false memories narrow down. As participants retain more and more information in their memory, false memory becomes more and more like true memory, and true memory more and more like false memory. Across different false memory studies, retention size could have been an uncontrolled variable and, hence, contributed to the varying degrees to which false memory was subjectively experienced like true memory.

We conclude that false memory can be distinguished from true memory both objectively and subjectively and that the graded RTs and confidence ratings within the old and new response categories are compatible with the concept of a single underlying familiarity dimension of recognition memory (Donaldson, 1996; Hirshman \& Henzler, 1998; Hirshman \& Master, 1997; M. B. Miller \& Wolford, 1999; Xu \& Bellezza, 2001).

\section{REFERENCES}

Anderson, N. H. (2001). Empirical direction in design and analysis. Mahwah, NJ: Erlbaum.

BENJAMIn, A. S. (2001). On the dual effects of repetition on false recog- 
nition. Journal of Experimental Psychology: Learning, Memory, \& Cognition, 27, 941-947.

Brown, N. R., BuCHANAN, L., \& CABEZA, R. (2000). Estimating the frequency of nonevents: The role of recollection failure in false recognition. Psychonomic Bulletin \& Review, 7, 684-691.

DeESE, J. (1959). On the prediction of occurrence of particular verbal intrusions in immediate recall. Journal of Experimental Psychology, 58, 17-22.

DONALDSON, W. (1993). Accuracy of $d^{\prime}$ and $A^{\prime}$ as estimates of sensitivity. Bulletin of the Psychonomic Society, 31, 271-274.

DonaLDSON, W. (1996). The role of decision processes in remembering and knowing. Memory \& Cognition, 24, 523-533.

Fabiani, M., Stadler, M. A., \& Wessels, P. M. (2000). True but not false memories produce a sensory signature in human lateralized brain potentials. Journal of Cognitive Neuroscience, 12, 941-949.

Gallo, D. A., McDermott, K. B., Percer, J. M., \& RoeDiger, H. L., III (2001). Modality effects in false recall and false recognition. Journal of Experimental Psychology: Learning, Memory, \& Cognition, 27, 339-353.

GRIER, J. B. (1971). Nonparametric indexes for sensitivity and bias: Computing formulas. Psychological Bulletin, 75, 424-429.

HanCoCK, T. W., Hicks, J. L., MARSH, R. L., \& RitSCHEL, L. (2003). Measuring the activation level of critical lures in the Deese RoedigerMcDermott paradigm. American Journal of Psychology, 116, 1-14.

Hirshman, E., \& HenZler, A. (1998). The role of decision processes in conscious recollection. Psychological Science, 9, 61-65.

Hirshman, E., \& Master, S. (1997). Modeling the conscious correlates of recognition memory: Reflections on the remember-know paradigm. Memory \& Cognition, 25, 345-351.

Hockley, W. E., \& Murdock, B. B. (1987). A decision model for accuracy and response latency in recognition memory. Psychological Review, 94, 341-358.

HowELL, D. C. (2002). Statistical methods for psychology. Pacific Grove, CA: Duxbury.

Johnson, M. K., Foley, M. A., Suengas, A. G., \& Raye, C. L. (1988). Phenomenal characteristics of memories for perceived and imagined autobiographical events. Journal of Experimental Psychology: General, 117, 371-376.

Johnson, M. K., Hashtroudi, S., \& Lindsay, D. S. (1993). Source monitoring. Psychological Bulletin, 114, 3-28.

Johnson, M. K., \& RAYE, C. L. (1981). Reality monitoring. Psychological Review, 88, 67-85.

Lampinen, J. M., NEuschatz, J. S., \& Payne, D. G. (1999). Source attributions and false memories: A test of the demand characteristics account. Psychonomic Bulletin \& Review, 6, 130-135.

Mather, M., HenKel, L. A., \& Johnson, M. K. (1997). Evaluating characteristics of false memories: Remember/know judgments and memory characteristics questionnaire compared. Memory \& Cognition, 25, 826-837.

MCDERMOTT, K. B. (1996). The persistence of false memories in list recall. Journal of Memory \& Language, 35, 212-230.

McDermott, K. B. (1997). Priming on perceptual implicit memory tests can be achieved through presentation of associates. Psychonomic Bulletin \& Review, 4, 582-586.

MCDERMOTt, K. B., \& Roediger, H. L., III (1998). Attempting to avoid illusory memories: Robust false recognition of associates persists under conditions of explicit warnings and immediate testing. Journal of Memory \& Language, 39, 508-520.

MCDERmott, K. B., \& WATSON, J. M. (2001). The rise and fall of false recall: The impact of presentation duration. Journal of Memory \& Language, 45, 160-176.

Miller, A. R., Baratta, C., Wynveen, C., \& Rosenfeld, J. P. (2001). P300 latency, but not amplitude or topography, distinguishes between true and false recognition. Journal of Experimental Psychology: Learning, Memory, \& Cognition, 27, 354-361.

Miller, M. B., \& Wolford, G. L. (1999). Theoretical commentary: The role of criterion shift in false memory. Psychological Review, 106, 298-405.

Neuschatz, J. S., Payne, D. G., Lampinen, J. M., \& Toglia, M. P.
(2001). Assessing the effectiveness of warnings and the phenomenological characteristics of false memories. Memory, 9, 53-71.

Nobel, R. A., \& ShIFFrin, R. M. (2001). Retrieval processes in recognition and cued recall. Journal of Experimental Psychology: Learning, Memory, \& Cognition, 27, 384-413.

NORMAN, K. A., \& SCHACTER, D. L. (1997). False recognition in younger and older adults: Exploring the characteristics of illusory memories. Memory \& Cognition, 25, 838-848.

PARDUCCI, A. (1984). Perceptual and judgment relativity. In V. Sarris \& A. Parducci (Eds.), Perspectives in psychological experimentation: Towards the year 2000 (pp. 135-149). Hillsdale, NJ: Erlbaum.

Payne, D. G., Elie, C. J., Blackwell, J. M., \& Neuschatz, J. S. (1996). Memory illusions: Recalling, recognizing, and recollecting events that never occurred. Journal of Memory \& Language, 35, 261285.

Rajaram, S., \& Roediger, H. L., III (1997). Remembering and knowing as states of consciousness during retrieval. In J. D. Cohen \& J. W. Schooler (Eds.), Scientific approach to consciousness (pp. 213-240). Mahwah, NJ: Erlbaum.

Roediger, H. L., III, \& McDermott, K. B. (1995). Creating false memories: Remembering words not presented in lists. Journal of Experimental Psychology: Learning, Memory, \& Cognition, 21, 803814.

Russell, W. A., \& Jenkins, J. J. (1954). The complete Minnesota norms for responses to 100 words from the Kent-Rosanoff Word Association Test (Tech. Rep. No. 11, Contract N8 ONR 66216, Office of Naval Research). Minneapolis: University of Minnesota.

SAS Institute (1985). SAS user's guide: Statistics (Version 5 ed.). Cary, NC: Author.

Seamon, J. G., Luo, C. R., Schwartz, M. A., Jones, K. J., Lee, D. M., \& JONES, S. J. (2002). Repetition can have similar or different effects on accurate and false recognition. Journal of Memory \& Language, 46, 323-340.

StADLER, M. A., Roediger, H. L., III, \& McDermott, K. B. (1999). Norms for word lists that create false memories. Memory \& Cognition, 27, 494-500.

Toglia, M. P., Neuschatz, J. S., \& Goodwin, K. (1999). Recall accuracy and illusory memories: When more is less. Memory, 7, 233-256.

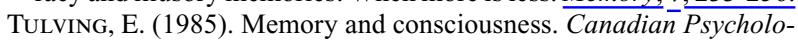
gist, 26, 1-12.

Tussing, A. A., \& Greene, R. L. (1999). Differential effects of repetition on true and false recognition. Journal of Memory \& Language, 40, 520-533.

UNDERWOOD, B. J. (1965). False recognition produced by implicit verbal responses. Journal of Experimental Psychology, 70, 122-129.

Westerberg, C. E., \& MarsoleK, C. J. (2003). Sensitivity reductions in false recognition: A measure of false memories with stronger theoretical implications. Journal of Experimental Psychology: Learning, Memory, \& Cognition, 29, 747-759.

XU, M., \& Bellezza, F. S. (2001). A comparison of the multimemory and detection theories of know and remember recognition judgments. Journal of Experimental Psychology: Learning, Memory, \& Cognition, 27, 1197-1210.

ZuCKerman, M., DePaulo, B. M., \& Rosenthal, R. (1981). Verbal and nonverbal communication of deception. In L. Berbowitz (Ed.), Advances in experimental social psychology (Vol. 14, pp. 1-59). New York: Academic Press.

\section{NOTES}

1. We used the term critical nonpresented words, instead of critical lures, throughout our article because the word lure implies that it is not presented, which was not always the case in our study, since half of the time they were presented and the other half of the time they were not presented in the first two experiments. The term critical words in our article can refer to either presented or nonpresented critical words. In this article, the term noncritical words can refer to either list words or noncritical distractor words. 
2. Two of the three RT studies cited here were brought to our attention by Jeffrey Anastasi.

3. Whether or not the know and remember experiences are two qualitatively and categorically different experiences, two different but overlapping experiences, or two points on a continuous dimension of familiarity or strength is currently a debated issue (see Rajaram \& Roediger, 1997, for a review)

4. The words in Russell and Jenkins's (1954) association norms were listed by descending association strength. Since Roediger and McDermott (1995) developed their word lists by taking the top 15 words in a chosen list of Russell and Jenkins's original word association norms (with some exceptions; see Roediger \& McDermott, 1995), we simply chose our additional 14 words from each corresponding list in Russell and Jenkins's norms by generally picking the next 14 words from that list (also with some exceptions; e.g., skipping a word or two in a list to avoid already used words).

5. The reason we excluded only the most extreme RT outliers was that we intended to include all the data except those from trials in which we suspected that the participants had responded before or simultaneously with the onset of the stimulus word (in which cases, an RT of zero was registered), had taken a brief rest, or had momentarily gotten distracted while the test word was being displayed.

6 . Because of the slightly unequal numbers of participants across the three presentation conditions and the unequal cell $n$ s across different response categories, the ANOVA conducted in this study was an analysis of variance procedure in the general linear model. The results reported are based on Type III sum of squares (Howell, 2002; SAS Institute, 1985).

7. See Donaldson (1993) for a comparison of $d^{\prime}$ and $A^{\prime}$ as sensitivity measures and Grier (1971) for the computational formula for $A^{\prime}$.

8 . Because none of the critical words was presented in this experiment, there were no hit measures and, hence, no $A^{\prime}$ measures for the critical words in this experiment.

9. Because a linear regression is more sensitive in detecting a linear trend than is an ANOVA (Anderson, 2001), we used linear regression several times in our data analyses to supplement an ANOVA when we suspected that the ANOVA results were not sufficiently informative. 


\section{APPENDIX}

\section{Lists of Semantically Associated Words}

The word enclosed in parentheses in each list is the critical nonpresented word for that list.

1. (anger), mad, fear, hate, rage, temper, fury, ire, wrath, happy, fight, hatred, mean, calm, emotion, enrage, hurt, disgust, hit, frustrate, friendly, sorrow, shout, sad, bad, joy, violence, dislike, yell, tears

2. (bread), butter, food, eat, sandwich, rye, jam, milk, flour, jelly, dough, crust, slice, wine, loaf, toast, white, knife, rolls, wheat, basket, hunger, yeast, starch, fresh, stale, meat, bun, raisin, moist

3. (chair), table, sit, legs, seat, couch, desk, recliner, sofa, wood, cushion, swivel, stool, sitting, rocking, bench, arm, back, leather, wheel, lazy, office, wicker, study, lamp, top, armchair, furniture, rug, room

4. (needle), thread, pin, eye, sewing, sharp, point, prick, thimble, haystack, thorn, hurt, injection, syringe, cloth, knitting, shots, stick, stack, tailor, embroidery, pine, pierce, thin, poke, head, spool, yarn, vaccine, string

5. (river), water, stream, lake, Mississippi, boat, tide, swim, flow, run, barge, creek, brook, fish, bridge, winding, deep, wide, wet, band, bank, ocean, long, rapid, sea, flood, pond, wash, drown, torrent

6. (window), door, glass, pane, shade, ledge, sill, house, open, curtain, frame, view, breeze, sash, screen, shutter, look, scene, outside, clear, picture, room, sight, wind, bright, wall, sun, air, home, storm

7. (slow), fast, lethargic, stop, listless, snail, cautious, delay, traffic, turtle, hesitant, speed, quick, sluggish, wait, molasses, drive, movement, go, runner, stall, halt, bus, steady, drag, pause, lazy, idle, tedious, easy

8. (music), note, sound, piano, sing, radio, band, melody, horn, concert, instrument, symphony, jazz, orchestra, art, rhythm, noise, play, score, harmony, choir, voice, drum, trumpet, opera, chord, record, composer, song, tune

9. (rough), smooth, bumpy, road, tough, sandpaper, jagged, ready, coarse, uneven, riders, rugged, sand, boards, ground, gravel, surface, stone, edge, file, shaggy, stormy, cement, tumble, crude, difficult, callous, rocky, tweed, terrain

10. (fruit), apple, vegetable, orange, kiwi, citrus, ripe, pear, banana, berry, cherry, basket, juice, salad, bowl, cocktail, fly, eat, tree, peach, grapes, flower, seed, nut, strawberry, jello, lemon, sour, tomato, vine

11. (sleep), bed, rest, awake, tired, dream, wake, snooze, blanket, doze, slumber, snore, nap, peace, yawn, drowsy, dead, lay, quiet, insomnia, relax, morning, lullaby, lull, nightmare, night, coma, late, clock, refresh

12. (king), queen, England, crown, prince, George, dictator, palace, throne, chess, rule, subjects, monarch, royal, leader, reign, Kong, cards, Henry, power, kingdom, lion, royalty, court, robe, scepter, empire, lord, majesty, tyrant

13. (cold), hot, snow, warm, winter, ice, wet, frigid, chilly, heat, weather, freeze, air, shiver, Arctic, frost, outside, fireplace, Minnesota, sneeze, wind, cough, temperature, shower, jacket, water, bitter, zero, shelter, icicle

14. (doctor), nurse, sick, lawyer, medicine, health, hospital, dentist, physician, ill, patient, office, stethoscope, surgeon, clinic, cure, throat, white, heal, pill, bill, well, operation, pain, visit, stitch, wound, cuts, call, life

15. (high), low, clouds, up, tall, tower, jump, above, building, noon, cliff, sky, over, airplane, dive, elevate, tide, ladder, hill, heals, top, moon, steep, fall, ceiling, wall, dizzy, perch, rise, reach

16. (girl), boy, dolls, female, young, dress, pretty, hair, niece, dance, beautiful, cute, date, aunt, daughter, sister, nice, skirt, lady, sex, love, she, baby, little, virgin, blond, smile, braids, party, child

17. (thief), steal, robber, crook, burglar, money, cop, bad, rob, jail, gun, villain, crime, bank, bandit, criminal, beggar, law, jewels, sneak, dishonest, murderer, accomplice, wrong, catch, property, flee, diamond, loot, purse

18. (black), white, dark, cat, charred, night, funeral, color, grief, blue, death, ink, bottom, coal, brown, gray, light, spade, red, board, hair, dirt, casket, satin, coat, pitch, dismal, velvet, hole, horse

19. (man), woman, husband, uncle, lady, house, male, father, strong, friend, beard, person, handsome, muscle, suit, old, wife, sports, big, superman, necktie, tough, football, cowboy, masculine, boss, figure, mustache, soldier, macho

20. (spider), web, insect, bug, fright, fly, arachnid, crawl, tarantula, poison, bite, creepy, animal, ugly, feelers, small, ant, fear, spin, widow, silk, trap, weave, corner, beetle, squirm, mites, cobweb, afraid, Halloween

21. (sweet), sour, candy, sugar, bitter, good, taste, tooth, nice, honey, soda, chocolate, heart, cake, tart, pie, lovely, milk, cute, saccharin, lips, scent, delicious, cookie, sticky, mellow, joy, smile, fragrant, eat

22. (soft), hard, light, pillow, plush, loud, cotton, fur, touch, fluffy, feather, furry, downy, kitten, skin, tender, silk, wool, mattress, mellow, mushy, gentle, sensitive, soothing, quilt, sponge, tissue, sweater, comfort, cuddly

23. (foot), shoe, hand, toe, kick, sandals, soccer, yard, walk, ankle, arm, boot, inch, sock, smell, mouth, leg, knee, ball, sore, wear, measure, finger, step, slipper, pedal, sole, print, stocking, sidewalk

24. (mountain), hill, valley, climb, summit, top, molehill, peak, plain, glacier, goat, bike, climber, range, steep, ski, stream, rock, lake, Everest, plateau, Yellowstone, canyon, cave, ridge, slopes, altitude, resort, land, path 